\title{
Clinical and epidemiological characteristics of pediatric and adolescent patients of COVID-19, an experience of a Divisional Corona Center, Bahawalpur from South Punjab, Pakistan.
}

\footnotetext{
1. MBBS, FCPS (Pediatrics) Senior Registrar Pediatric Medicine Quaid-E- Azam Medical College Bahawalpur.

2. MBBS, FCPS (Pediatrics) Associate Professor Pediatric Medicine

Quaid-E- Azam Medical College Bahawalpur.

3. MBBS, FCPS (Pediatrics) Assistant Professor Neonatology Quaid-E- Azam Medical College Bahawalpur.

4. MBBS, FCPS (Pediatrics) Professor Pediatric Medicine Quaid-E- Azam Medical College Bahawalpur.
}

Correspondence Address:

Dr. Ali Hammad

Department of Pediatric Medicine

Quaid-E- Azam Medical College

Bahawalpur

ali.hammad20@gmail.com

Article received on:

25/02/2021

Accepted for publication: 28/04/2021

\section{Ali Hammad1, Muhammad Naeem², Hafiz Muhammad Anwar ${ }^{3}$, Ameer Ahmad}

ABSTRACT... Objective: To assess various clinical and epidemiological characteristics of pediatric and adolescent patients of COVID-19 of Bahawalpur division, to improve their outcome and management. Study design: Descriptive Cohort study. Setting: Department of Pediatrics, Civil Hospital Bahawalpur. Period: $1^{\text {st }}$ March to $30^{\text {th }}$ July 2020 . Material \& Methods: Data of patients was recovered from hospital record. Data of variables like age, gender, rural or urban living area, symptomatology and need for hospitalization was collected from hospital record. Results: Out of total 516 diagnosed COVID-19 patients, 5.4\% patients were of age less than 20 years, $32 \%$ from birth to 5 years, 20\% from 6 to 10 years of age, $21.4 \%$ were 11 to 15 years of age, $28.5 \%$ were 16 to 20 years age group. $57.1 \%$ were male and $42.8 \%$ were female. $42.8 \%$ were asymptomatic, $32 \%$ patient had respiratory symptoms, $25 \%$ had Gastro-intestinal symptoms. $64.2 \%$ belonged to urban territory of living, $35.7 \%$ belonged to rural. $81.2 \%$ patients fall in mild category and $18.7 \%$ in moderate. Mortality was Null. Hospitalization was needed in $53.5 \%$, while $46.5 \%$ were home quarantined. Mean duration of hospital stay was $14+1$ days. Conclusion: Pediatric and adolescent patients have mild to moderate disease severity leading to better outcome of the disease.

Key words: $\quad$ Adolescent, COVID-19, Epidemiology, Mortality, Pediatric, Symptomatology.

Article Citation: Hammad A, Naeem M, Anwar HM, Ahmad A. Clinical and epidemiological characteristics of pediatric and adolescent patients of Covid-19, an experience of a Divisional Corona Center, Bahawalpur from South Punjab, Pakistan. Professional Med J 2021; 28(11):1616-1620. https://doi.org/10.29309/TPMJ/2021.28.11.6448

\section{INTRODUCTION}

During December 2019, A pneumonia of unknown cause began to spread rapidly in the city of Wuhan, Hubei province of China. ${ }^{1}$ The causative organism was named as novel corona virus (nCoV). ${ }^{2}$ It was initially named $2019-n C o V$ by World Health Organization (WHO). ${ }^{3}$ Later, renamed as Severe Acute Respiratory Syndrome Coronavirus-2 (SARS-CoV-2). ${ }^{4}$ On February 11, 2020, WHO named the disease as coronavirus disease 2019 (COVID-19). ${ }^{5}$ On March 11, 2020 WHO declared the novel coronavirus (COVID-19) outbreak a global pandemic. ${ }^{6}$ Pakistan's northern border is shared with China and western border is shared with Iran which was also badly affected. ${ }^{7}$

Pakistan had first case of COVID-19 on February 26, 2020 in Karachi. ${ }^{8}$ Government of Pakistan prepared and presented a plan called "The National Action Plan for Preparedness and
Response to Corona Virus Disease (Covid-19) Pakistan". Main objective of this plan was to ensure a timely, effective response throughout the country to curtail the spread of the virus. ${ }^{9}$ The pandemic management was carried out by National Disaster Management Authority (NDMA) in collaboration with The National Institute of Health (NIH).

A study conducted in China on COVID-19 patients concluded that children generally had milder symptoms and better outcome than adult patients. ${ }^{10}$ Various clinical and epidemiological characteristics of COVID-19 have been studied on adult patients and in China. ${ }^{11,12}$ As many factors including weather and living conditions, nutrition and immunity of local population can affect the spread of viral disease and course of illness and most of the studies on this pandemic are done in west where the conditions are different 
from our country and population. Therefore, to assess the various clinical and epidemiological characteristics of pediatric and adolescent patients of COVID-19 of Bahawalpur division for improvement in their outcome and management, it was needed to study these characteristics of COVID-19 affected Pediatric and adolescent patients in South Punjab.

\section{MATERIAL \& METHODS}

A Descriptive Cohort study was conducted at the department of Pediatric Medicine, Civil Hospital Bahawalpur in which we used the probability sampling technique and included all the COVD19 positive patients of age ranging from birth to 20 years and excluded all patients of age more than 20 years. After obtaining an Ethical review committee approval letter (No. 389/ DME/QAMC Bahawalpur) from Department of medical education (DME) of QAMC Bahawalpur, we retrospectively collected the data from hospital record and studied the epidemiological characteristics like age distribution, gender distribution, rural or urban distribution, duration of illness from onset of symptoms till the confirmation diagnosis, need for hospitalization, presenting symptoms, duration of stay in the hospital and the clinical outcome of the disease. Strict confidentiality of data was maintained. No harm was given to any study participant. Justice, fair play and no conflict of interest of all authors was ensured. No source of funding was used other than authors themselves. The diagnostic tool used was Real Time Polymerase Chain Reaction (RT $\square$ PCR) Nucleic Acid detection kits provided by NDMA all over Pakistan, which uses nasopharyngeal or oro-pharyngeal swab, tracheal aspirate or Broncho-alveolar lavage (BAL) specimens. A pre-defined clinical criterion ${ }^{13}$ for the severity of illness was used.

\section{OPERATIONAL DEFINITIONS}

\section{Asymptomatic}

A confirmed (RT-PCR positive) case without any clinical sign or symptom.

\section{Mild Disease}

A confirmed (RT-PCR positive) case with non- specific manifestations of upper respiratory tract or Gl tract infection but no clinical or radiological signs of pneumonia.

\section{Moderate Disease}

A confirmed case with radiological signs of pneumonia but no any danger sign present.

\section{Severe Disease}

A confirmed case with radiological evidence of pneumonia AND/ OR sepsis, septic shock, respiratory failure requiring oxygen or assisted ventilation, Multi Organ Dysfunction Syndrome, Acute Respiratory Distress Syndrome, any danger sign (severe dehydration, lethargy, altered sensorium, grunting, heart failure).

SPSS version-25 was used for statistical analysis of data and chi-square test was applied on the variables. $P$-Value $<0.05$ was taken as significant. Age distribution of patients was further divided into 4 groups including: Birth - 5years, 6 - 10 years, $11-15 y e a r s$ and $16-20$ years. Variables like age distribution, gender distribution, need for hospitalization, rural/urban distribution and symptomatology were expressed as percentages, while duration of hospital stay was expressed in mean.

\section{RESULTS}

During our study period total 516 patients were diagnosed COVID-19, out of which 28 patients $(5.4 \%)$ were of age less than 20 years. None of them had any co-morbidity. Out of these 28 patients, nine patients (32\%) were of age from birth to 5 years, five patients (20\%) were from 6 to 10 years of age, six patients $(21.4 \%)$ were from 11 to 15 years of age, eight patients (28.5\%) were from 16 to 20 years of age group. Of these 28 patients, sixteen patients $(57.1 \%)$ were male and 12 (42.8\%) were female. Hospitalization was needed in 15 (53.5\%) patients, while 13 (46.5\%) patients were quarantined in their homes. Out of all patients, twelve (42.8\%) were asymptomatic who were diagnosed during contact screening, nine $(32 \%)$ patients presented with predominant respiratory symptoms including cough, breathing difficulty, while 7 (25\%) patients presented with Gastrointestinal symptoms including diarrhea and vomiting. Out of all 28 patients, eighteen 
(64.2\%) belonged to urban territory of living, while $10(35.7 \%)$ belonged to rural territory. Out of 16 symptomatic patients, thirteen $(81.2 \%)$ patients fall in mild category and $3(18.7 \%)$ in moderate category. Mortality was Null in all patients from birth till 20 years of age.

The various clinical variables and characteristics studied, along with number of patients in each category is shown in Table-I. Moreover, the statistical analysis showed no significant relation among four age groups of pediatric patients and rural or urban living conditions ( $p$-Value $=0.47$ ) i.e Table-II. No significant relation was found among four age groups of pediatric patients and symptomatic or asymptomatic clinical presentation of the patients $(p-$ Value $=0.48)$ i.e Table-III. Mean hospital stay was $14+1$ day. Mean time from the onset of symptoms till the laboratory confirmation of diagnosis was $3.8+1.22$ days.

\begin{tabular}{|l|l|c|}
\hline \multicolumn{1}{|c|}{ Category } & \multicolumn{1}{c|}{ Variables } & Patients (\%) \\
\hline $\begin{array}{l}\text { Gender } \\
\text { Distribution }\end{array}$ & Male & $16(57.1 \%)$ \\
\cline { 2 - 3 } Area of living & Female & $12(42.8 \%)$ \\
\hline \multirow{2}{*}{$\begin{array}{l}\text { Need for } \\
\text { Hospitalization }\end{array}$} & Rural & $10(35.7 \%)$ \\
\cline { 2 - 3 } & Urban & $18(64.2 \%)$ \\
\hline \multirow{2}{*}{ Symptomatology } & Home quarantined & $15(53.5 \%)$ \\
\hline & Asymptomatic & $12(42.8 \%)$ \\
\cline { 2 - 3 } & $\begin{array}{l}\text { Respiratory } \\
\text { symptoms }\end{array}$ & $9(32 \%)$ \\
\cline { 2 - 3 } & Gl symptoms & $7(25 \%)$ \\
\hline
\end{tabular}

Table-I. Clinical variables and characteristics of study population $(n=28)$.

\begin{tabular}{|l|c|c|c|c|c|c|c|}
\hline \multirow{2}{*}{ Living Area } & \multicolumn{7}{|c|}{ Age Group } \\
\cline { 2 - 7 } & $\begin{array}{c}\text { Birth-5 yrs } \\
\text { N (\%) }\end{array}$ & $\begin{array}{c}\mathbf{6 - 1 0} \text { years } \\
\text { n (\%) }\end{array}$ & $\begin{array}{c}\text { 11-15years } \\
\text { n (\%) }\end{array}$ & $\begin{array}{c}\mathbf{1 6 - 2 0 y e a r s} \\
\mathbf{n}(\%)\end{array}$ & $\begin{array}{c}\text { Total } \\
\text { N (\%) }\end{array}$ & $\begin{array}{c}\text { Chi sq. } \\
\text { value }\end{array}$ & P-Value \\
\hline Urban(n) & $5(27.5 \%)$ & $4(22.2 \%)$ & $5(27.7 \%)$ & $4(22.2 \%)$ & $18(100 \%)$ & & \\
\hline Rural(n) & $4(40 \%)$ & $1(10 \%)$ & $1(10 \%)$ & $4(40 \%)$ & $10(100 \%)$ & 2.49 & 0.47 \\
\hline Total(n) & $9(32 \%)$ & $5(20 \%)$ & $6(21.4 \%)$ & $8(28.5 \%)$ & $28(100 \%)$ & & \\
\hline
\end{tabular}

Table-II. Living condition and age groups of patients.

\begin{tabular}{|c|c|c|c|c|c|}
\hline \multirow[t]{2}{*}{ Age } & \multicolumn{2}{|c|}{ Symptoms } & \multirow[b]{2}{*}{ Total n(\%) } & \multirow[b]{2}{*}{ Chi-sq. Value } & \multirow[b]{2}{*}{ P-Value } \\
\hline & Symptomatic n (\%) & Asymptomatic (\%) & & & \\
\hline Birth-5 yrs(n) & $4(44.4 \%)$ & $5(55.5 \%)$ & $9(100 \%)$ & \multirow{5}{*}{2.45} & \multirow{5}{*}{0.48} \\
\hline $6-10$ yrs $(n)$ & $2(40 \%)$ & $3(60 \%)$ & $5(100 \%)$ & & \\
\hline $11-15$ yrs(n) & $4(66.6 \%)$ & 2(33.3\%) & $6(100 \%)$ & & \\
\hline $16-20$ yrs(n) & $6(75 \%)$ & $2(25 \%)$ & $8(100 \%)$ & & \\
\hline Total(n) & $16(57.1 \%)$ & $12(42.8 \%)$ & $28(100 \%)$ & & \\
\hline
\end{tabular}

Table-III. Symptomatology of pediatric patients of various age groups.

\section{DISCUSSION}

COVID-19 is a rapidly spreading and highly contagious disease causing life threatening pneumonia and other complications. Research work is going on in all parts of the world and many new clinical manifestations have been studied, especially in pediatric population. Understanding the clinical features of the virus is essential to improve the treatment options and prepare a vaccine in near future.

As found in previous studies ${ }^{14,15}$, the findings of our study also showed that the main symptoms of COVID-19 in children were respiratory i,e. Fever, dry cough and pneumonia. Pediatric patients mostly acquired COVID-19 from their close family members and household contacts. Among the pediatric and adolescent patients in our study, most had mild course of illness. One patient who became moderately sick requiring oxygen inhalation and intensive care monitoring had pneumonia which was confirmed with chest X-ray. Generally, children have mild disease, shorter duration of illness and lesser need for hospitalization and shorter stay in hospital. One reason for that could be that children rarely have 
any comorbidity like hypertension, cardiovascular disease, obesity and diabetes. Although more research work is needed to explore the contributing factors in this better outcome.

An interesting outcome of our study was that majority of the patient's belonged to urban region. Probable reasons behind that could be better immune status of rural population, people in rural areas live in more spacious and well ventilated houses while over-crowding of urban areas, living in closed spaces with poor ventilation may contribute to more spread of the virus or may be less reporting from rural areas due to less awareness. However, further studies are required to explore the reasons behind this finding. Analysis of clinical presentation of patients of various age groups showed that 11-20 years age group had the most number of asymptomatic patients of COVID-19. Therefore, this age group needs a special consideration while screening the contacts as they can be silent carrier of the virus and pose a risk for the elderly people in their homes. It was found in our study that in younger age groups, most of the patients were asymptomatic in under 20 years patient. Although more research is needed to find the reasons but one explanation could be that older patients were exposed to more affected individuals as they spent more time outside their homes than the younger patients. Mean hospital stay was 14 days as initially most of the patients were admitted in hospital irrespective of their disease severity. Lately the policy of home quarantine was devised to reduce hospital admission and stay. A study concluded that the clinical outcome of COVID-19 varied among different ethnic groups of the population, $36.1 \%$ children needed hospitalization, among them $33.2 \%$ were admitted to an intensive care unit (ICU), 5.8\% required invasive mechanical ventilation, and one patient died during hospitalization. ${ }^{16}$ Another study showed that outcome was worsened by the co-morbid conditions of the patients. ${ }^{17} \mathrm{~A}$ study done on pediatric COVID-19 patients admitted in Intensive care unit concluded that majority (83\%) of the affected patients had a pre-existing comorbidity which made the outcome poor. ${ }^{18}$
The major limitation of our study was the small sample size. Possible reasons behind this are that people in general have many misconceptions regarding this pandemic. Many people were reluctant to go to the hospital and getting tested for COVID-19, if they had any such symptom. Government also tried its best and used all means of communication to spread genuine information but still much more is needed to be done in this regard. Moreover, due to ongoing research, the policies regarding screening, isolation and hospitalization of the patients kept on changing with the passage of time. Since COVID-19 is spreading more, we have presented an early report on pediatric and adolescent patients but we are sure that with on-going research additional data will be collected and more knowledge will be added which will certainly help in understanding this disease better.

\section{CONCLUSION}

Pediatric and adolescent patients have mild to moderate disease severity leading to better outcome of the disease.

Copyright $@ 28$ Apr, 2021.

\section{REFERENCES}

1. Wu P, Hao X, Lau EH, Wong JY, Leung KS. Realtime tentative assessment of the epidemiological characteristics of novel coronavirus infections in Wuhan, China, as at 22 January 2020. Euro Surveill. 2020; 25(3):2000044. doi: 10.2807/1560-7917. ES.2020.25.3.2000044.

2. Lu R, Zhao X, Li J, Niu P, Yang B et al. Genomic characterization and epidemiology of 2019 novel coronavirus: Implications for virus origins and receptor binding. Lancet Infect Dis. 2020; 395(10224):565-74. doi: 10.1016/S0140-6736(20)302518. Epub 2020 Jan 30.

3. Zhu N, Zhang D, Wang W, Li X, Yang B. A novel coronavirus from patients with pneumonia in China, 2019. N Eng J Med. 2020; 382 (4): 301-394. doi: 10.1056/NEJMoa2001017. Epub 2020 Jan 24.

4. Gorbalenya AE, Baker SC, Baric R, Groot RJ, Drosten C. Severe acute respiratory syndrome-related coronavirus: The species and its viruses-a statement of the Coronavirus Study Group. Nat. Microbiol. 2020 Apr; 5(4):536-544. doi: 10.1038/s41564-0200695-z. Epub 2020 Mar 2. 
5. World Health Organization. Novel Coronavirus (2019nCoV): Situation report, 3. Website: [https://www. who.int/emergencies/diseases/novel-coronavirus-2019/ situation-reports]. Retrieved on January $23^{\text {rd }}, 2020$.

6. Cucinotta D, Vanelli M. WHO declares COVID-19 a pandemic. Acta Biomed Atenei Parmensis. 2020; 91(1):157-160.

7. Saqlain M, Munir MM, Ahmed A, Tahir AH, Kamran $\mathrm{S}$. Is Pakistan prepared to tackle the coronavirus epidemic?. Drugs There Perspect.2020; 36 (5): 213214. DOI: $10.1007 / \mathrm{s} 40267-020-00721-1$.

8. Ali I, Shah SA, Siddiqui N. Pakistan confirms first two cases of coronavirus, Govt says "no need to panic". DAWN. Website: [https://www.dawn.com/].Retrieved on February $26^{\text {th }}, 2020$.

9. Sherin A. Preparedness and response of Pakistan for coronavirus disease 2019: Gaps and Challenges. Khyber Med. Univ. J. 2020; 12(2):79-80. https://doi. org/10.35845/kmuj.2020.20450.

10. Ludvigsson JF. Systematic review of COVID $\square 19$ in children shows milder cases and a better prognosis than adults. Acta Paediatrica. 2020; 109(6):1088-1095. DOI: 10.1111/apa.15270.

11. She J, Liu L, Liu W. COVID $\square 19$ epidemic: Disease characteristics in children. J Med Virol. 2020; 92(9) 1501-1510. DOI: 10.1002/jmv.25807.

12. Dong $\mathrm{Y}, \mathrm{Mo} \mathrm{X}, \mathrm{Hu} \mathrm{Y}$, Qi $\mathrm{X}$, Jiang $\mathrm{F}$, Jiang $Z$, etal. Epidemiology of COVID-19 among children in China. Am Acad Pediatrics. 2020; 145(6):370-374. DOI: 10.1542/peds.2020-0702.
13. Hamid MH, Afzal MF, Noor M. COVID-19 in ChildrenWhat is known so far. Pak Paed J. 2020; 44(2):157-76.

15. Lu X, Zhang L, Du H, Zhang J, Li YY, Qu J, etal. SARSCoV-2 infection in children. N Engl J Med. 2020; 382(17):1663-1665. DOI: 10.1056/NEJMc2005073.

16. Du W, Yu J, Wang $H$, Zhang $X$, Zhang S. Clinical characteristics of COVID-19 in children compared with adults in Shandong Province, China. Infect. 2020; 48(3):445-452. DOI: 10.1007/s15010-020-014272.

17. Kim L, Whitaker M, Halloran OA, Kambhampati A, Chai $\mathrm{SJ}$ et al. Hospitalization Rates and Characteristics of Children Aged $<18$ Years Hospitalized with LaboratoryConfirmed COVID-19 - COVID-NET, 14 States, March 1-July 25, 2020. MMWR Morb Mortal Wkly Rep. 2020 Aug 14; 69(32):1081-1088. DOI: $10.15585 / \mathrm{mmwr}$. $\mathrm{mm} 6932 \mathrm{e} 3$.

18. COVID-NET, 14 States, MMWR Morb Mortal Wkly Rep. 2020 Aug 14; 69(32): 1081-1088. Published online 2020 Aug 14.

19. Blumfield E, Levin TL. COVID-19 in pediatric patients: A case series from the Bronx, NY. Pediatr. Radiol. 2020; 50(10): 1369-1374. DOI: 10.1007/s00247-02004782-2.

20. Shekerdemian LS, Mahmood NR, Wolfe KK, Riggs BJ, Ross CE. Characteristics and outcomes of children with coronavirus disease 2019 (COVID-19) infection admitted to US and Canadian pediatric intensive care units. JAMA Peads. 2020; 174(9): 868-873. https:// doi.org/10.1001/jamapediatrics.2020.1948.

\begin{tabular}{|c||l|l|l|}
\hline \multicolumn{3}{|c|}{ AUTHORSHIP AND CONTRIBUTION DECLARATION } \\
\hline No. & \multicolumn{1}{|c|}{ Author(s) Full Name } & \multicolumn{1}{|c|}{ Contribution to the paper } & Author(s) Signature \\
\hline 1 & Ali Hammad & $\begin{array}{l}\text { Conceived data, Data } \\
\text { collection, Data introduction, } \\
\text { Statistical analysis. } \\
\text { Literature review. }\end{array}$ \\
\hline 3 & Muhammad Naeem & Hafiz Muhammad Anwar & \\
\hline 4 & Ameer Ahmad & $\begin{array}{l}\text { Manuscript writing. } \\
\text { Manuscript final reading and } \\
\text { approval. }\end{array}$ \\
\hline
\end{tabular}

